RATs are commonly used in anaphylaxis models, mainly in intestinal anaphylaxis. Hypersensitivity mechanisms are complex and they are not clearly defined. Ovalbumin (OVA) is commonly used for studies on the hypersensitivity mechanism. However, the potential pro-inflammatory mediators induced by this antigen in the model of paw oedema in immunized rats are still not completely understood. This work examines the pharmacological modulation of several mediators involved in rat hind paw immune oedema induced by OVA. Wistar rats were previously immunized (14-18 days) with OVA $(30 \mu \mathrm{g}$, intraperitoneally) or sham-sensitized with aluminum hydroxide (control). The paw volumes were measured before the antigenic stimuli and 1, 2, 3 and $4 \mathrm{~h}$ after the intraplantar injection of OVA $(10 \mu \mathrm{g} / \mathrm{paw})$. Subcutaneous injection of dexamethasone, diphenhydramine, cyproheptadine, chlorpromazine or methysergide significantly inhibited $(p<0.05)$ the allergic paw oedema. The dual inhibitor of cyclooxygenase and lipoxygenase (NDGA), the cyclooxygenase inhibitor (indomethacin), the lipoxygenase inhibitor (MK886), the PAF antagonist (WEB 2086), the mast cell stabilizer (ketotifen), and the anti-histamine (meclizine) did not inhibit the immune oedema. In addition, thalidomide and pentoxifylline (anti-tumour necrosis factor drugs) were ineffective against OVA-induced oedema. The fact that indomethacin, MK-886, NDGA and WEB 2086 are unable to inhibit this allergic oedema indicates that the dexamethasone action seems not to be via phospholipase A2, but possibly due to the synthesis and/or the inhibitory activity of cytokines. The paw oedema inhibition by diphenhydramine, but not by meclizine, may suggest a different mechanism, which is independent of the effect of histamine. These data indicate that allergic oedema is more sensitive to anti-serotonin drugs, mainly anti5-HT2, suggesting that the principal mediator of this inflammatory response is serotonin.

Key words: Rat paw immune oedema, Anti-inflammatory drug, Anti-allergic drug, Ovalbumin

\section{The pharmacological profile of ovalbumin-induced paw oedema in rats}

\author{
R. F. G. Feitosa ${ }^{1, C A}$, G. B. Melcíades ${ }^{2}$, A. M. S.
} Assreuy $^{3}$, M. F. G. Rocha ${ }^{2}$, R. A. Ribeiro ${ }^{1}$ and A. A. M. Lima ${ }^{1}$

${ }^{1}$ Institute of Biomedicine, Clinical Research Unit, Department of Physiology and Pharmacology, Faculty of Medicine, Federal University of Ceara, Av. José Bastos 3390, C.P. 3229 Porangabussu, Fortaleza, CE, CEP 60436-160, Brazil; ${ }^{2}$ Faculty of Veterinary Science, and ${ }^{3}$ Department of Physiological Sciences, CCS, State University of Ceara, Fortaleza, CE, Brazil

\footnotetext{
${ }^{\mathrm{CA}}$ Corresponding author:

Tel: +55852888440

Fax: +55852815212

E-mail: rgfeitosa@ig.com.br
}

\section{Introduction}

Allergic processes are complex disorders in which inflammatory and immunological mechanisms are involved. One of the most important approaches used in the examination of the immunopathological mechanisms of anaphylactic and inflammatory disorders is to elicit the formation of paw oedema, injecting various substances into the subplantar tissue of rats or mice. ${ }^{1}$ Inflammation often occurs after a subplantar injection of a number of substances in the hind paw of rats or mice. Many anti-inflammatory drugs have been tested for their ability to inhibit hind paw oedema.

The vasoactive amines, histamine and serotonin, play a crucial role in type I hypersensitivity. ${ }^{2-4}$ The most important vasoactive mediators that are stored in mast cells and basophil granules are histamine in humans, as well as serotonin (5-hydroxytryptamine) in rodents. Histamine was one of the first inflammatory mediators thought to be important in the pathophysiology of asthma. ${ }^{5}$ Like histamine, serotonin is also capable of increasing vascular permeability, of dilating capillaries and of producing the contraction of non-vascular smooth muscles. Most serotonin is stored in the gastrointestinal tract and the central nervous system, but a large amount is also stored in the dense granules of platelets. ${ }^{6}$

Rats are commonly used in the study of anaphylaxis, particularly those involving the intestinal tract. $^{7,8}$ Pre-clinical studies are necessary for prospective research on physiopathology of food allergy. 
There have been no studies, to our knowledge, of paw oedema specifically induced by ovalbumin (OVA) antigen in the rat. To perform studies in intestinal hypersensitivity, we decided to evaluate the potency of OVA using this antigen for immunization in the model of rat hind paw oedema. This study investigated the protective effect of several pharmacological inhibitors in the course of the immune oedema, to determine which mediators are involved in antigeninduced oedema. We initially investigated the importance of classic antagonists of inflammation in the development of antigen-induced oedema, in the paws of sensitized rats. The protective effects of antihistamine and anti-allergic agents against anaphylactic oedema were also studied.

\section{Materials and methods}

Animals

Wistar rats (130-230 g body weight) of both sexes were housed in a room with free access to water and food until used. All animals were supplied by Clinical Research Unit, Federal University of Ceará, and the protocol complied with the Occupational Health and Safety in the Care and Use of Research Animals.

\section{Sensitization procedure}

OVA was dissolved in phosphate-buffered saline (PBS) and mixed with an equal volume of coloidal aluminium hydroxide, $\mathrm{Al}(\mathrm{OH})_{3}$. The rats were sensitized on day 0 by intraperitoneal (i.p.) injections of $30 \mu \mathrm{g}$ of OVA/rat dispersed in $0.5 \mathrm{ml}$ of $\mathrm{PBS}$ and $\mathrm{Al}(\mathrm{OH})_{3}$. The control rats were injected with an emulsion containing equal volumes of $\mathrm{PBS}$ and $\mathrm{Al}(\mathrm{OH})_{3}$.

\section{Quantification of immune paw oedema}

Fourteen to 18 days after the injection of antigen to sensitization or $\mathrm{Al}(\mathrm{OH})_{3}$ (sham-sensitization), the animals received an intraplantar injection of $10 \mu \mathrm{g}$ of OVA in the right hind paw, diluted in $100 \mu$ l of PBS. The volume of the hind paw of each animal was measured by plethysmograph (7150 plethysmomether; Ugo Basile, Varese, Italy) before the injection of the inflammatory challenge (time 0 ) and 1, 2, 3 and $4 \mathrm{~h}$ after the challenge. The increase in paw volume ( $\Delta$ volume) was obtained by subtracting the paw volume measured prior to the application of stimuli from the volumes for the different timepoints. The results were expressed as the increase in paw volume $(\mathrm{ml})$ calculated by subtracting the basal volume. The area under the time-course curve was also calculated and the results expressed in arbitrary units. ${ }^{9,10}$
Drug modulation of OVA-induced paw oedema in immunized rats

In the present study employing specific antagonists, we investigated the importance of various putative mediators of inflammation in the development of the oedema induced by OVA, in the hindpaw of sensitized rats. The effects of anti-inflammatory, anti-histamine and anti-allergic drugs against anaphylactic paw oedema were studied.

\section{Drug administration}

One hour before the intraplantar challenge, animals were treated subcutaneously (s.c.) with inhibitors. The drugs were diluted in sterile PBS. In control animals, sterile PBS replaced the antagonists. Most of the doses used in this study have commonly been shown in the literature to inhibit the corresponding binding sites. ${ }^{4,11,12}$

\section{Systemic depletion of mast cells ${ }^{13}$}

Animals were pretreated i.p. with compound 48/80 during 4 days $(0.6 \mathrm{mg} / \mathrm{kg}$, twice a day for 3 days and $1.2 \mathrm{mg} / \mathrm{kg}$, twice on the $4 \mathrm{th}$ day). On the 5 th day, the intraplantar challenge was made and the oedema was evaluated. Animals were killed by cervical dislocation $4 \mathrm{~h}$ after the paw challenge, and the depletion of mast cell population was estimated in groups of treated animals by counting the number of mast cells in the peritoneal cavity exudate, using toluidine blue.

\section{Histopathological study}

Animals were killed by cervical dislocation $4 \mathrm{~h}$ after the paw challenge. The paws were excised and the footpads fixed in $10 \%$ formalin solution. Paraffin blocks were prepared using conventional techniques and the histological sections stained with haematoxylin and eosin for light microscopic analysis.

\section{Drugs and reagents}

The following drugs and reagents were used: chicken OVA, dimethyl sulfoxide, compound 48/80, cromolyn, ketotifen, cyproheptadine, diphenydramine, pentoxyfilline, indomethacin, nordihydroguaiaretic acid, NDGA (Sigma, St Louis, MO, USA), MK-886 (L-663,536(3-[1-(4-chlorobenzyl)3-t-butyl-thio-5-isopropylindol-2-yl]-2,2 dimethylpropanoic acid) (Calbiochem, Calbiochem, La Jolla, CA, USA), tienotriazolobenzodiazepinic compound (WEB 2086; Institute Pasteur, Paris, France), methysergide (maleate; Sandoz/Novartis, Cambridge, MA, USA), meclizine (Pfizer, São Paulo, SP, Brazil), thalidomide (CEME, Brasília, Brazil), chlorpromazine (Rhodia Farma, Săo Paulo, SP, Brazil), dexamethasone (Decadron; Merck Sharp \& Dohme, São Paulo, SP, 


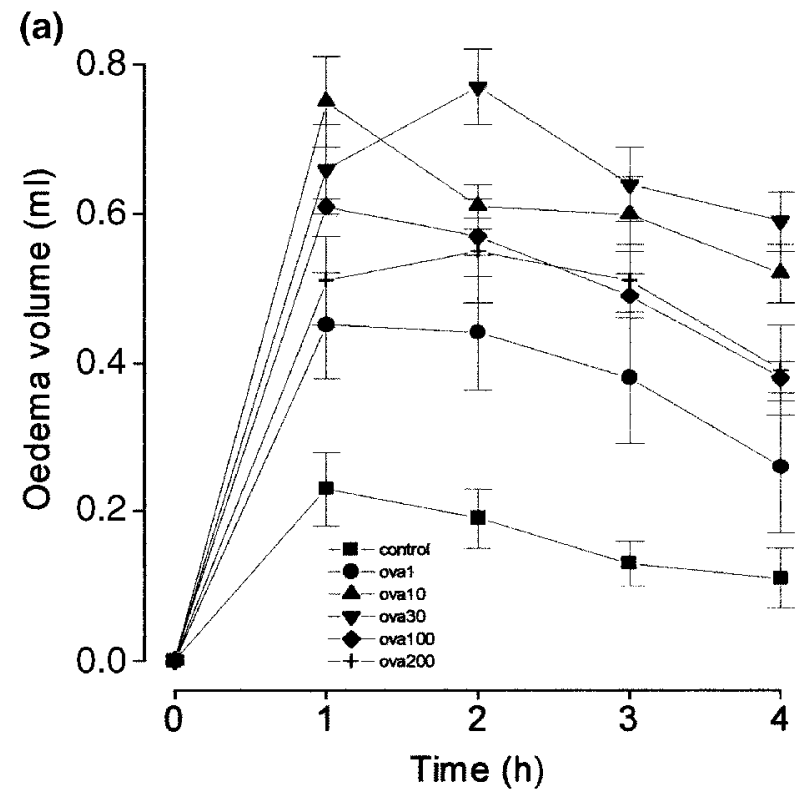

(b)

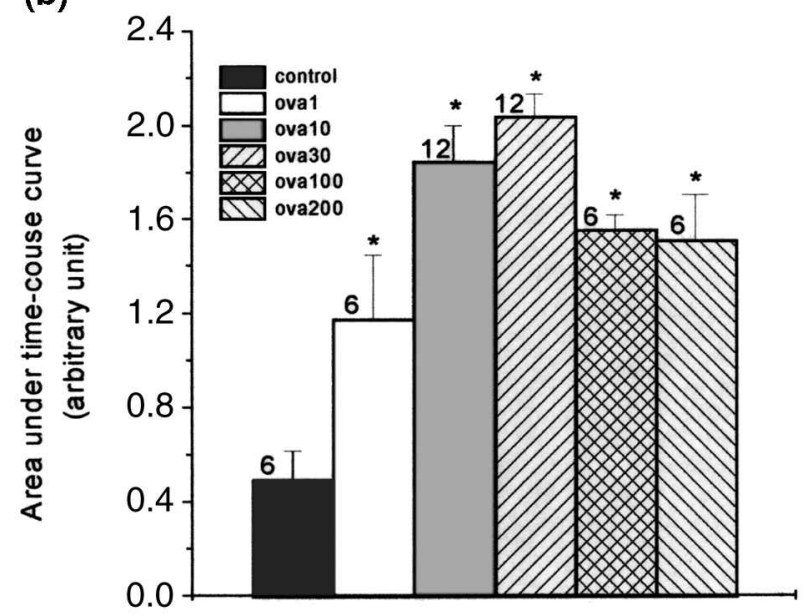

FIG. 1. Dose-dependence course of sensitization of rats prior induction of ovalbumin (ova) - paw oedema. (a) Rats were sham-sensitized with $\mathrm{Al}(\mathrm{OH})_{3}$ (control) or pre-sensitized with ova at the doses indicated ( $\mu \mathrm{g} / \mathrm{rat}$ ) and 14-18 days after challenge were intraplantar injected $(10 \mu \mathrm{g} / \mathrm{paw})$. Oedema was evaluated 1, 2, 3 and $4 \mathrm{~h}$ after challenge. (b) The area under the time-course curve was determined using a trapezoidal rule. Each point represents the mean \pm SEM for the number of animals indicated. *Significant differences compared with the sham-sensitized (control) $(p<0.05$; ANOVA, Student's $t$-test).

Brazil), and coloidal aluminum hydroxide (Sanofi, Rio de Janeiro, RJ, Brazil).

\section{Statistical analysis}

The results are expressed as means \pm standard error of the mean (SEM). Statistical evaluation was undertaken by analysis of variance (ANOVA) following Student's paired $t$-test. Statistical differences were considered significant at $p<0.05$.

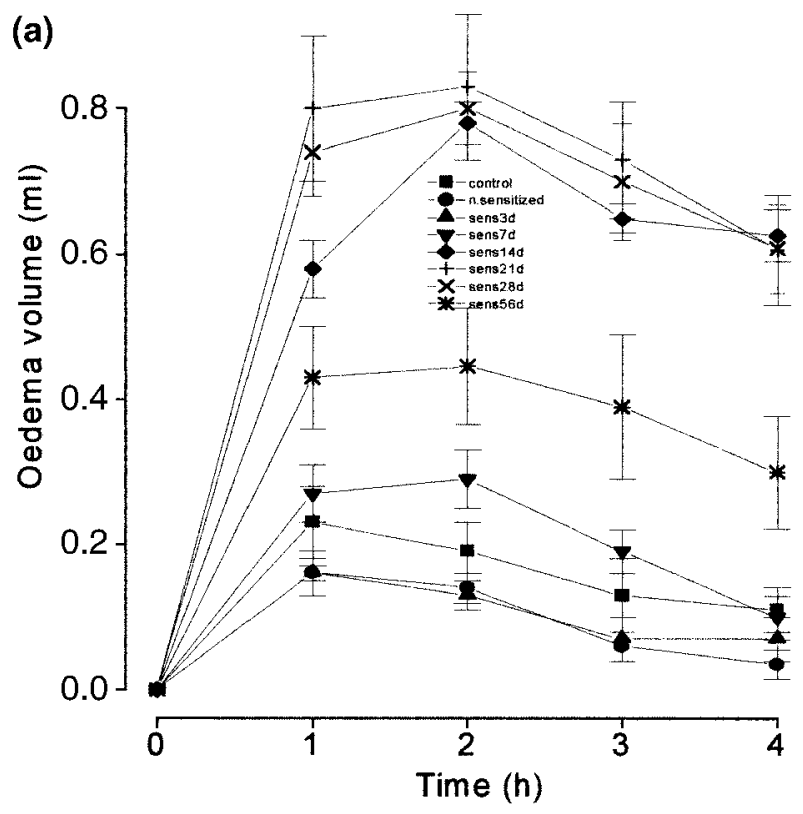

(b)

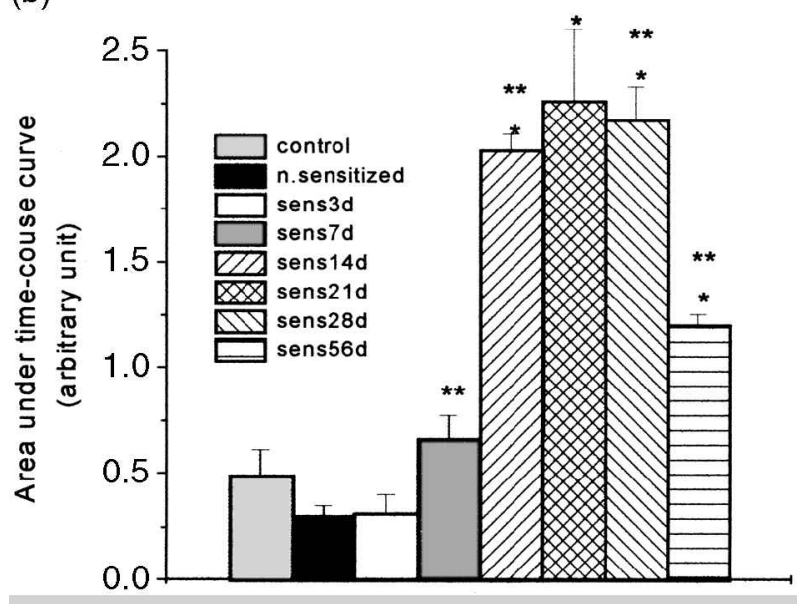

FIG. 2. Time course of sensitization of rats prior induction of ovalbumin (ova) - paw oedema. (a) Oedema induced by ova $(10 \mu \mathrm{g} / \mathrm{paw})$ injected in sham-sensitized (control), non-sensitized (n.sensitized) or sensitized sens rats with ova ( $30 \mu \mathrm{g} / \mathrm{rat}$ ) at different days (d) after sensitization. (b) The area under the time-course curve was determined using a trapezoidal rule. Each point represents the mean \pm SEM for the number of animals $(n=6)$. Significant differences compared with respective controls: * compared with the sham-sensitized group (control) or ** compared with the not-sensitized group $(p<0.05 ;$ ANOVA, Student's $t$-test).

\section{Results}

\section{Dose dependence and time-course of paw oedema induced by OVA}

The intraplantar injection of $10 \mu \mathrm{g} / \mathrm{paw}$ of OVA induced a sustained oedema in rats immunized with OVA at doses up to $200 \mu \mathrm{g} / \mathrm{rat}$ (Fig. 1). At the lowest doses $(10 \mu \mathrm{g} / \mathrm{rat})$ of sensitization, the oedema had a rapid onset, peaking $1 \mathrm{~h}$ after injection. For the dose used in this study $(30 \mu \mathrm{g} / \mathrm{rat}$ to sensitization and 
Table 1. Failure of standard agents to inhibit paw oedema induced by OVA in sensitized rats

\begin{tabular}{|c|c|c|c|c|c|}
\hline \multirow[t]{2}{*}{ Treatment $^{\mathrm{a}}$} & \multirow{2}{*}{$\begin{array}{l}\text { Dose } \\
(\mathrm{mg} / \mathrm{kg})\end{array}$} & \multicolumn{4}{|c|}{ Time } \\
\hline & & 1 & 2 & 3 & 4 \\
\hline PBS $(n=6)$ & & $0.70 \pm 0.10$ & $0.65 \pm 0.06$ & $0.60 \pm 0.04$ & $0.53 \pm 0.03$ \\
\hline $\begin{array}{l}\text { Indomethacin ( } n=6 \text { ) (cyclo-oxygenase } \\
\text { inhibitor) }\end{array}$ & 2 & $0.73 \pm 0.05$ & $0.63 \pm 0.03$ & $0.6 \pm 0.05$ & $0.52 \pm 0.05$ \\
\hline MK-886 ( $n=5)$ (5-lipoxygenase inhibitor) & 10 & $0.54 \pm 0.09$ & $0.57 \pm 0.10$ & $0.48 \pm 0.08$ & $0.39 \pm 0.09$ \\
\hline $\begin{array}{l}\text { NDGA }(n=5) \text { (cyclooxygenase and } \\
\text { lipoxygenase inhibitor) }\end{array}$ & 60 & $0.72 \pm 0.06$ & $0.80 \pm 0.08$ & $0.72 \pm 0.07$ & $0.60 \pm 0.06$ \\
\hline WEB $2086(n=6)$ (PAF antagonist) & 5 & $0.58 \pm 0.02$ & $0.60 \pm 0.04$ & $0.54 \pm 0.03$ & $0.46 \pm 0.03$ \\
\hline Ketotifen ( $n=6)$ (mast cell stabilizer) & 10 & $0.62 \pm 0.03$ & $0.55 \pm 0.02$ & $0.56 \pm 0.03$ & $0.50 \pm 0.03$ \\
\hline Combination $(n=6)^{\mathrm{b}}$ & - & $0.56 \pm 0.06$ & $0.59 \pm 0.03$ & $0.58 \pm 0.02$ & $0.52 \pm 0.02$ \\
\hline
\end{tabular}

Data expressed as the mean \pm SEM of the increase in paw volume $(\mathrm{ml})$.

a Ovalbumin $(10 \mu \mathrm{g} / 100 \mu \mathrm{l})$ was intraplantar injected and oedema was measured after 1, 2, 3 and $4 \mathrm{~h}$. Number of animals/group in parentheses.

${ }^{\mathrm{b}}$ Combination $=$ indomethacin + MK $886+$ ketotifen at indicated doses.

$10 \mu \mathrm{g} / \mathrm{paw}$ to challenge), the oedema reached a peak at about $2 \mathrm{~h}$ after the challenge, followed by a gradual decrease thereafter, and at $24 \mathrm{~h}$ post injection it was almost absent. Furthermore, the oedema increased up to 21 days after sensitization (Fig. 2), while the highest doses $(200 \mu \mathrm{g} / \mathrm{rat})$ induced a long-lasting oedema, which increased up to 28 days after sensitization (data not shown). Non-sensitized or control groups sham-sensitized with $\mathrm{Al}(\mathrm{OH})_{3}$ were not affected by intraplantar OVA.

\section{Response of OVA-induced oedema to standard antagonists}

Pretreatment of the animals with dexamethasone $(0.5 \mathrm{mg} / \mathrm{kg})$ was effective in inhibiting allergic oedema. Using non-steroidal anti-inflammatory agents, indomethacin ( $2 \mathrm{mg} / \mathrm{kg})$, MK-886 (10 mg/kg), NDGA $(60 \mathrm{mg} / \mathrm{kg})$ and WEB $2086(5 \mathrm{mg} / \mathrm{kg})$, we found that cyclooxygenase and lypoxygenase prod- ucts do not participate in the reaction. The combination of indomethacin $(2 \mathrm{mg} / \mathrm{kg})+$ MK-886 (10 mg/ $\mathrm{kg})+$ ketotifen $(10 \mathrm{mg} / \mathrm{kg})$ also failed to reduce the oedema induced by OVA (Table 1). All used doses have previously been shown to inhibit the corresponding pathways of arachidonic acid metabolism in rats. ${ }^{11}$

\section{The role of mast cell and endogenous amines on OVA-induced oedema}

Vasoactive amines appear to be involved because anti-histamine and anti-serotonin agents reduced the oedema. A significant inhibition of OVA-induced oedema was observed with methysergide (anti-serotonin), diphenydramine (anti-histamine) and cyproheptadine (anti-histamine and anti-serotonin) (Table 2 , and Figs 3 and 4). Inhibition induced by diphenydramine was dose dependent for all doses (25, 50, 75 and $100 \mathrm{mg} / \mathrm{kg}$, s.c.). The highest dose $(100 \mathrm{mg} /$ $\mathrm{kg}$ ) almost completely blocked oedema formation by

Table 2. Effect of anti-histamine and anti-allergic drugs on the time course of paw oedema induced by OVA in sensitized rats

\begin{tabular}{|c|c|c|c|c|c|}
\hline \multirow[t]{2}{*}{ Treatment ${ }^{\mathrm{a}}$} & \multirow{2}{*}{$\begin{array}{c}\text { Dose } \\
(\mathrm{mg} / \mathrm{kg})\end{array}$} & \multicolumn{4}{|c|}{ Time } \\
\hline & & 1 & $2 \mathrm{~h}$ & $3 h$ & $4 \mathrm{~h}$ \\
\hline PBS $(n=6)$ & & $0.70 \pm 0.10^{c}$ & $0.65 \pm 0.06$ & $0.60 \pm 0.04$ & $0.53 \pm 0.03$ \\
\hline Meclizine $(n=5)\left(\mathrm{H}_{1}\right.$ anti-histamine $)$ & 30 & $0.64 \pm 0.06$ & $0.52 \pm 0.04$ & $0.55 \pm 0.05$ & $0.47 \pm 0.07$ \\
\hline Methysergide $(n=5)\left(5-\mathrm{HT}_{2}\right.$ blocker $)$ & 5 & $0.21 \pm 0.04^{*}$ & $0.36 \pm 0.06^{*}$ & $0.25 \pm 0.06^{*}$ & $0.26 \pm 0.07^{*}$ \\
\hline Ketotifen $(n=6)$ (mast cell stabilizer) & 10 & $0.62 \pm 0.03$ & $0.55 \pm 0.02$ & $0.56 \pm 0.03$ & $0.50 \pm 0.03$ \\
\hline Cromolyn ( $n=6)$ (mast cell stabilizer) & 5 & $0.73 \pm 0.06$ & $0.87 \pm 0.06^{*}$ & $0.72 \pm 0.04$ & $0.61 \pm 0.05$ \\
\hline $\begin{array}{l}\text { Compound } 48 / 80 \text { ( } n=6 \text { ) (depletor of mast } \\
\text { cell) }\end{array}$ & & $0.85 \pm 0.05$ & $0.92 \pm 0.03^{*}$ & $0.84 \pm 0.05^{*}$ & $0.68 \pm 0.03^{*}$ \\
\hline Dexamethasone ( $n=5)$ (glucocorticoid) & 0.5 & $0.29 \pm 0.02 *$ & $0.41 \pm 0.02 *$ & $0.38 \pm 0.03^{*}$ & $0.23 \pm 0.02 *$ \\
\hline
\end{tabular}

Data expressed as the mean \pm SEM of the increase in paw volume $(\mathrm{ml})$.

a Ovalbumin $(10 \mu \mathrm{g} / 100 \mu \mathrm{l})$ was intraplantar injected and oedema was measured after 1, 2, 3 and $4 \mathrm{~h}$. Number of animals/group in parentheses.

${ }^{*} p<0.05$ (ANOVA, Student's $t$-test), compared with the PBS group. 
(a)

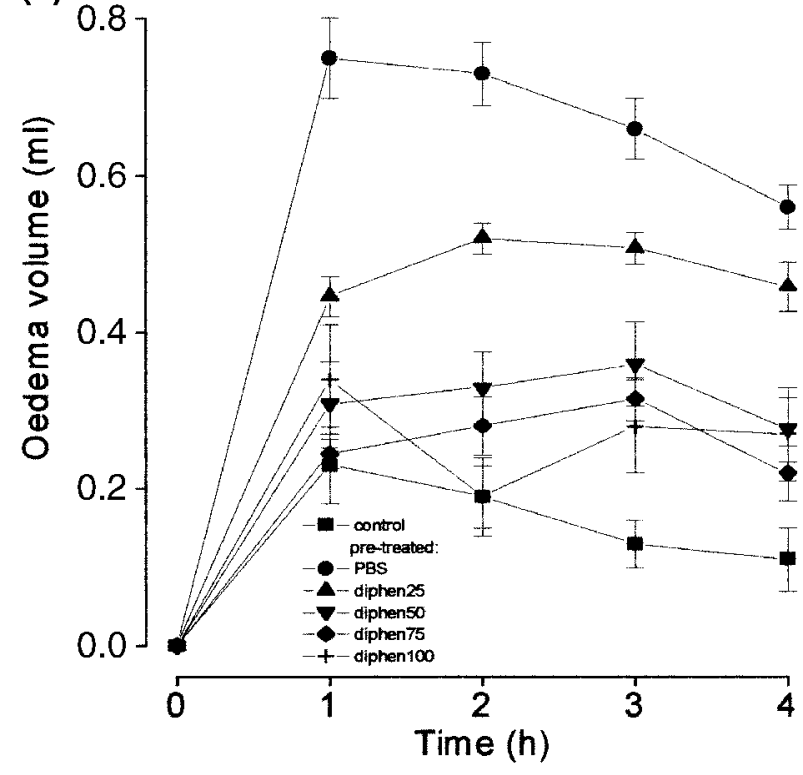

(b)

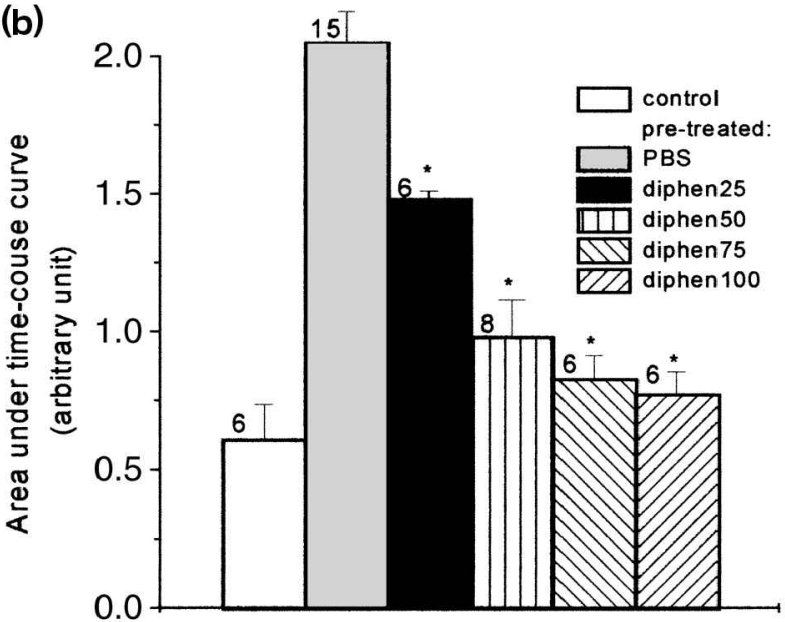

FIG. 3. Inhibition by diphenydramine (diphen; anti- $\mathrm{H}_{1}$ ) of rat paw oedema induced by intraplantar injection of ovalbumin (ova; $10 \mu \mathrm{g} / \mathrm{paw}$ ) in sensitized rats. Fourteen to 18 days before, animals were sham-sensitized (control) or sensitized with ovalbumin $(30 \mu \mathrm{g} / \mathrm{rat}$, i.p.) and treated $1 \mathrm{~h}$ before intraplantar challenge, with PBS or diphenydramine s.c. at the doses indicated. (a) Oedema was measured 1, 2, 3 and $4 \mathrm{~h}$ after the inflammatory challenge and expressed as the increase in paw volume ( $\mathrm{ml}$ ) above its basal volume. (b) The area under the time-course curve was determined using a trapezoidal rule. Each point represents the mean \pm SEM for the number of animals indicated. * Significant statistical differences compared with the PBS group $(p<0.05$; ANOVA, Student's $t$-test).

OVA (Fig. 3). In contrast, meclizine (classical anti- $\mathrm{H}_{1}$ ) failed to inhibit immune oedema.

\section{Effect of mast cell stabilizer agents and compound $48 / 80$ on oedema induced by OVA}

Pretreatment of animals with cromolyn (disodium cromoglycate) slightly influenced the oedema (a)
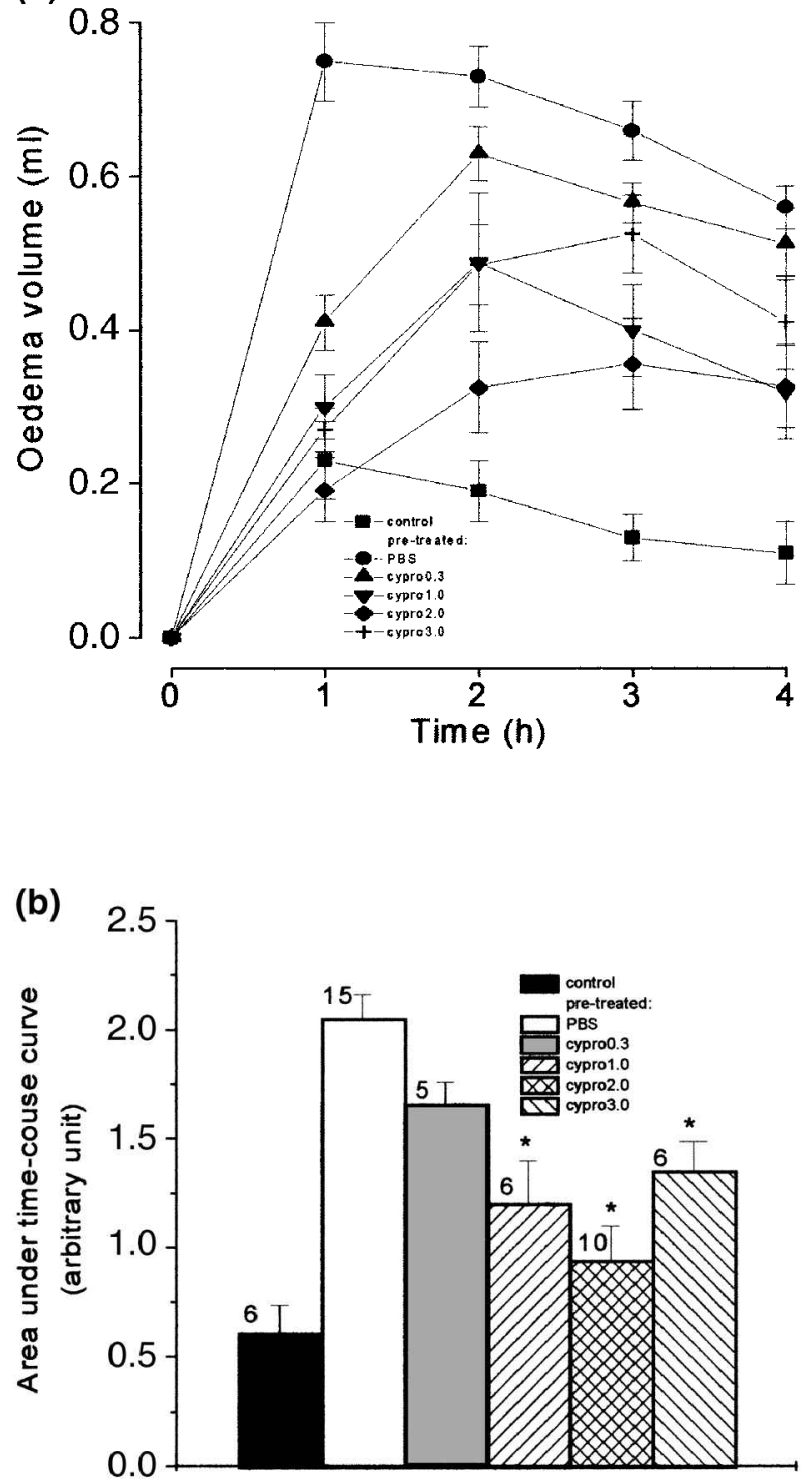

FIG. 4. Inhibition by cyproheptadine (cypro; anti- $\mathrm{H}_{1} / 5-\mathrm{HT}_{2}$ ) of rat paw oedema induced by intraplantar injection of ovalbumin (ova; $10 \mu \mathrm{g} / \mathrm{paw}$ ) in sensitized rats. Fourteen to 18 days before, animals were sensitized with ovalbumin (30 $\mu \mathrm{g} / \mathrm{rat}$, i.p.) and treated $1 \mathrm{~h}$ before intraplantar challenge, with PBS or cyproheptadine s.c. at the doses indicated (mg/ $\mathrm{kg}$ ). (a) Oedema was measured 1, 2, 3 and $4 \mathrm{~h}$ after the inflammatory challenge and expressed as the increase in paw volume $(\mathrm{ml})$ above its basal volume. (b) The area under the time-course curve was determined using a trapezoidal rule. Each point represents the mean \pm SEM for the number of animals indicated. * Significant statistical differences compared with the PBS group $(p<0.05$; ANOVA, Student's $t$-test).

induced by OVA even at doses up to $20 \mathrm{mg} / \mathrm{kg}$. Cromolyn induced stimulation at a lower dose of $5 \mathrm{mg} / \mathrm{kg}$ that was only detectable at $2 \mathrm{~h}$ (Table 2 ). On the contrary, ketotifen $(10 \mathrm{mg} / \mathrm{kg})$ was not effective (Table 2). In addition, the depletion of mast cells by systemic treatment with compound 48/80 slightly, but significantly, increased the oedematogenic response (Table 2). 
Table 3. Effect of anti-TNF drugs on the time-course of paw oedema induced by OVA in sensitized rats

\begin{tabular}{|c|c|c|c|c|c|}
\hline \multirow[t]{2}{*}{ Treatment ${ }^{\mathrm{a}}$} & \multirow{2}{*}{$\begin{array}{c}\text { Dose } \\
\text { (mg/kg) }\end{array}$} & \multicolumn{4}{|c|}{ Time } \\
\hline & & 1 & 2 & 3 & 4 \\
\hline $\begin{array}{l}\text { PBS }(n=6) \\
\text { Thalidomide }(n=6)^{\mathrm{b}} \\
\text { Penthoxyfilline }(n=6)\end{array}$ & $\begin{array}{l}90 \\
90\end{array}$ & $\begin{array}{l}0.68 \pm 0.08 \\
0.65 \pm 0.07 \\
0.64 \pm 0.03\end{array}$ & $\begin{array}{l}0.69 \pm 0.07 \\
0.71 \pm 0.07 \\
0.64 \pm 0.04\end{array}$ & $\begin{array}{l}0.59 \pm 0.04 \\
0.66 \pm 0.06 \\
0.50 \pm 0.04\end{array}$ & $\begin{array}{l}0.52 \pm 0.03 \\
0.63 \pm 0.06 \\
0.48 \pm 0.05\end{array}$ \\
\hline
\end{tabular}

Data expressed as the mean \pm SEM of the increase in paw volume $(\mathrm{ml})$.

a Ovalbumin $(10 \mu \mathrm{g} / 100 \mu \mathrm{l})$ was intraplantar injected and oedema was measured after 1, 2, 3 and $4 \mathrm{~h}$. Number of animals/group in parentheses.

b Thalidomide vehicle (dimethyl sulfoxide) did not alter the oedematogenic response.

\section{Response of immune oedema to anti-tumour necrosis factor drugs}

In the present work, the effect of drugs like thalidomide, inhibitors of tumour necrosis factor (TNF) release, ${ }^{14}$ and pentoxyfilline, inhibitor of TNF and interleukin-1 synthesis, ${ }^{15,16}$ was investigated. Table 3 shows that thalidomide $(90 \mathrm{mg} / \mathrm{kg}$ ) and pentoxyfilline $(90 \mathrm{mg} / \mathrm{kg})$ did not affect the oedema induced by OVA in rats. However, a significant inhibition by chlorpromazine (inhibitor of TNF synthesis) was noted for all doses (Table 4).

\section{Histological study of the rat paws after antigenic challenge}

An intense infiltration of neutrophils and eosinophils was observed in the hypodermis of the paws injected with OVA.

\section{Discussion}

Our results clearly demonstrate that immune oedema do not appear to be dependent on arachidonic acid metabolism, since the cyclooxygenase inhibitor (indomethacin), the 5 -lipoxygenase inhibitor (MK886) and the PAF antagonist (WEB 2086), or the combination of indomethacin + MK-886 + ketotifen, exerted no significant inhibition on this oedema, when tested at doses that have been commonly used. On the contrary, dexamethasone had a marked inhibitory effect on the oedema.

The inhibitory effect of dexamethasone on oedema of the rat paw induced by OVA is probably not due to interference with eicosanoid formation, since drugs that block cyclooxygenase and lipoxygenase were ineffective. Several effects of glucocorticoids may be explained by their capacity to block the release of chemotactic mediators as the metabolites of arachidonic acid and/or cytokines with inflammatory properties. ${ }^{17,18}$ The inhibitory effect of dexamethasone on allergic oedema may result, at least in part, from the inhibition of the release of inflammatory cytokines. On the contrary, many studies indicate that the adhesion molecules are upregulated in allergic inflammation, and play a critical role in the pathogenesis of allergic inflammation. ${ }^{19}$ Yamaki et al. ${ }^{20}$ analyzed the role and mode of action of the mast cell mediator histamine in leucocyte-endothelium interactions in small venules in vivo. The authors suggested that the polymorphonuclear leukocytes rolling were sensitive to glucocorticoid treatment, possibly via the inhibition of the expression or function of leukocytic P-selectin ligant(s).

The role of vasoactive amines was also investigated in this experiment. The effect of two chemically

Table 4. Effect of chlorpromazine (anti-TNF/5- $\mathrm{HT}_{2}$ ) on the time course of paw oedema induced by OVA in sensitized rats

\begin{tabular}{|c|c|c|c|c|c|}
\hline \multirow[t]{2}{*}{ Treatment $^{\mathrm{a}}$} & \multirow{2}{*}{$\begin{array}{c}\text { Dose } \\
(\mathrm{mg} / \mathrm{kg})\end{array}$} & \multicolumn{4}{|c|}{ Time } \\
\hline & & 1 & 2 & 3 & 4 \\
\hline PBS $(n=15)$ & & $0.75 \pm 0.05$ & $0.73 \pm 0.04$ & $0.66 \pm 0.04$ & $0.56 \pm 0.03$ \\
\hline Chlorpromazine $(n=6)$ & 1 & $0.50 \pm 0.06^{*}$ & $0.55 \pm 0.05^{*}$ & $0.46 \pm 0.05^{*}$ & $0.42 \pm 0.05^{*}$ \\
\hline Chlorpromazine $(n=6)$ & 3 & $0.55 \pm 0.07^{*}$ & $0.58 \pm 0.08 *$ & $0.51 \pm 0.07^{*}$ & $0.4 \pm 0.06^{*}$ \\
\hline Chlorpromazine $(n=6)$ & 9 & $0.26 \pm 0.05^{*}$ & $0.29 \pm 0.02 *$ & $0.28 \pm 0.05^{*}$ & $0.23 \pm 0.04^{*}$ \\
\hline Chlorpromazine $(n=6)$ & 18 & $0.29 \pm 0.04 *$ & $0.34 \pm 0.4^{*}$ & $0.29 \pm 0.04 *$ & $0.31 \pm 0.03 *$ \\
\hline
\end{tabular}

Data expressed as the mean \pm SEM of the increase in paw volume $(\mathrm{ml})$.

a Ovalbumin $(10 \mu \mathrm{g} / 100 \mu \mathrm{l})$ was intraplantar injected and oedema was measured after 1, 2, 3 and $4 \mathrm{~h}$. Number of animals/group in parentheses.

${ }^{*} p<0.05$ (ANOVA, Student's $t$-test), compared with the PBS group. 
distinct hydrogen antagonists, meclizine and diphenydramine, was tested. It was found that only diphenydramine caused reduction in the immune oedema in a dose-dependent manner. In addition, methysergide (serotonin antagonist) inhibited OVAinduced oedema with optimal effect at a dose of $5 \mathrm{mg} / \mathrm{kg}$, as well as cyproheptadine (histamine and serotonin antagonist), suggesting the involvement of endogenous amines, probably serotonin.

Although diphenhydramine has a well-established $\mathrm{H}_{1}$ anti-histamine action, its anti-oedematogenic effect in the sensitized rat may not necessarily be associated with this property, since meclizine (classical anti- $\mathrm{H}_{1}$ ) failed to block the oedema. Thus, histamine seems not to be involved. Meclizine's lack of effect is not surprising, since histamine is not an important mediator of vascular permeability in rats. ${ }^{21}$ Tromp et $a l .{ }^{22}$ investigated the role of mast cells and histamine in leukocyte-endothelium interactions in four rat strains: Brown Norway, Lewis, Sprague-Dawley and Wistar. In Sprague-Dawley rats, the topical administration of histamine $\left(10^{-4} \mathrm{M}\right)$ resulted in a significant increase in the level of leukocyte rolling and a decrease in the rolling velocity compared with the time control. Histamine induced leukocyte adhesion only in the Brown Norway strain.

Additionally, studies have apparently divided the anti-histamine drugs into two classes: those compounds that release histamine and serotonin from isolated rat peritoneal mast cells, and those that inhibit the release of these mediators by compound $48 / 80 .^{12}$ Possible different effects of the anti-histamine drugs have also been investigated. Diphenhydramine appears to be effective in inhibiting serotonin uptake. ${ }^{23}$ Maling et al. ${ }^{12}$ showed that diphenhydramine inhibits oedema induced by serotonin in rats. Thus, we speculate a possible effect of this drug on the depletion of serotonin.

Serotonin is a naturally occurring amine with major effects on a variety of bodily functions. ${ }^{24}$ Important studies concerning serotonin have focused on vascular and inflammatory responses. Owen ${ }^{25}$ suggested that administering serotonin to the plantar surface of the rat hind paw caused oedema with striking extravasation of albumin. Serotonin was also reported to induce plasma extravasation as a result of oedema formation in other models. ${ }^{26,27}$ In addition, cyproheptadine is a drug that shows high affinity for serotonin type $2\left(5-\mathrm{HT}_{2}\right)$ receptors. ${ }^{28}$ Honrubia et al. ${ }^{28}$ showed that the activity of cyproheptadine derivatives at $5-\mathrm{HT}_{2}$ receptors is related to these molecular features, which make feasible a common disposition to interact with all three $5-\mathrm{HT}_{2}$ subtypes. Since methysergide, primarily a serotonin type 2 $\left(5-\mathrm{HT}_{2}\right)$ antagonist, ${ }^{29}$ and cyproheptadine, anti$\mathrm{H}_{1} / 5-\mathrm{HT}_{2},{ }^{28,30}$ are active inhibitors of oedema, we suggest that serotonin may be an important mediator in the formation of oedema induced by OVA in sensitized rats, being the binding site of the receptor 5-HT ${ }_{2}$.

On the contrary, the mast cell stabilizer compounds, cromolyn and ketotifen, had a slight or no effect in this oedema. Cromolyn (disodium cromoglycate) pretreatment only slightly influenced the inflammatory response. Results showed that cromolyn at lower doses $(5 \mathrm{mg} / \mathrm{kg})$ slightly and temporarily $(2 \mathrm{~h})$ increased the oedema, whereas at higher doses $(20 \mathrm{mg} / \mathrm{kg})$ it slightly reduced the oedema only in young rats (about $130 \mathrm{~g}$ body weight) (data not shown). The action of cromolyn on inflammation remains uncertain. This drug inhibits mast cell degranulation and has a direct effect on inflammatory cells. Shida ${ }^{31}$ suggests that cromolyn probably, non-specifically, targets the surface of relevant cells including mast cells and eosinophils. In addition, some studies suggest that cromolyn diminishes cell activation. ${ }^{19,32}$ In this study, the stimulatory effect at lower doses suggests that the involvement of mast cells may be in the inhibition of this oedema, while the inhibitory effect at higher doses in young rats may be due to a direct effect on immune-inflammatory immature cells, or due to another mechanism of unknown basis.

Compound 48/80 is known as a potent inducer of degranulation and of the release, from connective tissue-type mast cells, of histamine and other chemical mediators, which are responsible for anaphylactic syntoms. ${ }^{1}$ In this work, OVA-induced oedema was given potential by subchronic treatment by the mast cell degranulator compound $48 / 80$. Thus, the involvement of mast cells may occur in the inhibition of this oedema.

Histological analysis of the hind-paw $4 \mathrm{~h}$ after the paw challenge showed an intense infiltration of neutrophils and eosinophils in the hypodermis of the paws injected with OVA (data not shown). Considering that in the OVA-injected paw there is a migration of neutrophils and eosinophils to the extravascular tissues, we attributed the contribution of leukocyte migration to the development of allergic oedema. In addition, TNF $\alpha$ induces neutrophil migration in immune inflammation. ${ }^{33}$ Thus, we investigated the possibility that TNF $\alpha$ could be responsible for the neutrophils' chemotactic activity. Anti-TNF agents were ineffective against OVA-induced oedema. Pentoxifylline is a methylxanthine-derivative drug that has been used for more than 20 years in the treatment of peripheral vascular disease. Pentoxifylline is also a potent inhibitor of TNF $\alpha$ secretion, both in vitro and in vivo, and has demonstrated its efficacy in the treatment of certain animal and human inflammatory diseases. ${ }^{16}$ Furthermore, thalidomide exerts its inhibitory action on TNF $\alpha$ by enhancing mRNA degradation. ${ }^{14}$ Our data suggest that the factor responsible for inducing cell migration is different from $\mathrm{TNF} \alpha$, since 
thalidomide and pentoxifylline did not inhibit the immune oedema.

Additionally, in this study a wide range of doses were used for chlorpromazine (inhibitor of TNF synthesis and implicated in several others functions), due to exploreing this new literature data in this specific model. A significant inhibition by this drug was noted at all doses in this study. At higher doses $(18 \mathrm{mg} / \mathrm{kg})$, chlorpromazine produced a highly significant reduction in the oedematogenic effect. Chlorpromazine, a phenothiazine derivative, possesses antiinflammatory properties, inhibiting $\mathrm{TNF} \alpha$ synthesis and bone resorption. ${ }^{34}$ Also, the anti-serotonin effects of chlorpromazine at the $5 \mathrm{HT}_{2}$ site have been well characterized. $^{35}$ Trichard et al. ${ }^{36}$ suggest a high level of $5-\mathrm{HT}_{2 \mathrm{~A}}$ blockage with high doses of chlorpromazine. Its anti-histamine properties, however, are less well known.

In conclusion, the present work shows that the fact that indomethacin, MK-886, NDGA and WEB 2086 have not been able to inhibit allergic oedema, indicating that the action of dexamethasone seems not to be via phospholipase $A_{2}$, but possibly due to the synthesis and/or activity inhibition of pro-inflammatory cytokines or via the inhibition of expression or function of adhesion molecules. Our results suggest that anaphylactic rat paw oedema is independent of histamine action. The paw oedema inhibition by diphenhydramine, but not by meclizine (classical anti- $\mathrm{H}_{1}$ ), may suggest a different mechanism, which is independent from the anti-histamine effect. These data suggest a role for serotonin in the rat oedema induced by OVA, since methysergide and cyproheptadine were active inhibitors of this oedema. Thus, we speculate that serotonin is largely responsible for immunological oedema in rats, via 5- $\mathrm{HT}_{2}$ receptors, besides a possible involvement of other mediators, probably cytokines.

\section{ACKNOWLEDGEMENTS. Research supported by FUNCAP.}

\section{References}

1. Guo Y, Mochizuki T, Morii, E, Kitamura Y, Maeyama K. Role of mast cell histamine in the formation of rat paw edema: a microdialysis study. Eur J Pharmacol 1997; 331: 237-243.

2. Casey FB, Tokuda S. A comparative study of the mechanism of passive cutaneous anaphylaxis induced by mouse IgG, rabbit $\mathrm{F}\left(\mathrm{ab}^{\prime}\right)_{2}$ antibodies Int Arch Allergy 1973; 144: 737.

3. Kaneta S, Kanbara H, Fujihira E, Mitsuya M. Mouse Ig-E-mediated paw anaphylaxis in mice and rats. Int Arch Allergy Appl Immunol 1986; 80 333.

4. Amorim CZ, Cordeiro RS, Vargaftig BB. Interference of antihismines and anti-allergic drugs with antigen-induced paw edema in boosted and unboosted mice. Eur J Pharmacol 1992; 216: 429-434.

5. Bissonnette EY. Histamine inhibits tumor necrosis factor alpha release by mast cells through $\mathrm{H} 2$ and $\mathrm{H} 3$ receptors. Am J Respir Cell Mol Biol 1996 ; 14: $620-626$.

6. Kim DY, Camilleri M. Serotonin: a mediator of the brain-gut connection. Am J Gastroenterol 2000; 95: 2698-2709.

7. Perdue MH, Chung M, Gall DG. Effect of intestinal anaphylaxis on gut function in the rat. Gastroenterology 1984; 86: 391-397.

8. Scott RB, Tan DTM, Miampamba M, Sharkey KA. Anaphylaxis-induced alterations in intestinal motility: role of extrinsic neural pathways. Am J Physiol 1998; 275: G812-G821.
9. Lesser ML, Brown KI, Helson L. Statistical methods for measuring and comparing treatment efficacy application to nude mice experimentations. Exp Cell Biol 1980; 418: 126-137.

10. Landucci ECT, Antunes, Donato JL, et al. Inhibition of carragenin-induced rat paw oedema by crotapotin, a polypeptide complexed with phospholipase A2. Br J Pharmacol 1995; 114: 578-583.

11. Rocha MFG, Maia MET, Bezerra LRPS, Lyerly DM, Guerrant RL, Ribeiro RA, Lima AAM. Clostridium difficile toxin A induces the release of neutrophil chemotactic factors from rat peritoneal macrophages: role of interleukin-1 $\beta$, tumor necrosis factor alpha, and leukotrienes. Infect Immun 1997; 65: 2740-2746.

12. Maling HM, Webster ME, Williams MA, Saul W, Anderson WJ. Inflammation induced by histamine, serotonin, bradykinin and compound 48/80 in the rat: antagonists and mechanisms of action.J Pharmacol Exp Ther 1974; 191: 300-310.

13. Di Rosa M, Giroud JP, Willoughby DA. Studies of the mediators of the acute inflammatory response induced in rats in different sites by carrageenin and turpentine. J Patbol 1971; 104: 15-29.

14. Moreira AL, Sampaio EP, Zmuidzinas A, Frindt P, Smith KA, Kaplan G. Thalidomide exerts its inhibitory action on tumor necrosis factor alpha by enhancing mRNA degradation. J Exp Med 1993; 177: 1675-1680.

15. Endres S, Fulle HJ, Sinha B, Stoll D, Dinarello CA, Gerzer R, Weber PC. Cyclic nucleotides differentially regulate the synthesis of tumour necrosis factor-alpha and interleukin-1 beta by human mononuclear cells. Immunology 1991; 72: 56-60.

16. Pollice PF, Rosier RN, Looney RJ, Puzas JE, Schwarz EM, O'Keefe RJ. Oral pentoxifylline inhibits release of tumor necrosis factor-alpha from human peripheral blood monocytes: a potential treatment for aseptic loosening of total joint components. J Bone Joint Surg Am 2001; 83A: 1057-1061.

17. Dinarello CA. The proinflammarory cytokines interleukin-1 and tumor necrosis factor and treatment of the septic shock syndrome. J Infect Dis 1991; 163: 1177-1184.

18. Da Motta JI, Cunha FQ, Vargaftig BB, Ferreira SH. Drug modulation of antigen-induced paw oedema in guinea-pigs: effects of lipopolysaccharide, tumor necrosis factor and leucocyte depletion. Br J Pharmacol 1994; 112: 111-116.

19. Jahnová E, Horváthová M, Gazdik F. Expression of adhesion molecules and effect of disodium cromoglycate treatment in asthmatics. Physiol Res 1998; 47: 439-443.

20. Yamaki K, Thortacius H, Xie X, Lindbom L, Hedqvist P, Raund J. Characteristics of histamine-induced leucocyte rolling in the undisturbed microcirculation of the rat mesentery. Br J Pharmacol 1998; 123: 390-399.

21. Wilhelm DL. The mediation of increased vascular permeability in inflammation. Pharmacol Rev 1962; 14: 251-280.

22. Tromp SC, Talgelder GJ, Slaaf DW, et al. The role of mast cells and histamine in leukocyte-endothelium interactions in four rat strains. Pflugers Arch 1998; 436: 255-261.

23. Yeh SY, Dersch C, Rothman R, Cadet JL. Effects of antistamines on 3,4-methylenedioxymethamphetamine-induced depletion of serotonin in rats. Synapse 1999; 33: 207-217.

24. Lee $\mathrm{HZ}$, Wu $\mathrm{CH}$. Serotonin-induced protein kinase $\mathrm{C}$ activation in cultured rat heart endothelial cells. Eur J Pharmacol 2000; 403: 195-202

25. Owen DAA. Vascular changes during acute inflammation responses in rat hindpaws. In: Willoughby DA, Giroud JP, Velo GP, eds. Perspectives in Inflammation. London: MTP, 1977: 491-495.

26. Pierce PA, Xie GX, Peroutka SJ, Green PG, Levine JD. 5-Hydroxytryptamine-induced synovial plasma extravasation is mediated via 5-hydroxytryptamine 2 A receptors on sympathetic efferent terminals. $J$ Pharmacol Exp Ther 1995; 275: 502-508.

27. Wang JP, Chen YH, Kuo SC. Inhibition of hind-paw edema and cutaneous vascular plasma extravasation by 2-chloro-3-methoxy-carbonylpropionamido-1,4-naphthoquinone (PPIDI) in mice. Naunyn-Schmiedeberg's Arch Pharmacol 1996; 354: 779-784.

28. Honrubia MA, Rodriguez J, Dominguez R, Lozoya E, Manaut F, Seijas JA, Villaverde MC, Calleja JM, Cadavid MI, Maayani S, Sanz F, Loza MI. Synthesis, affinity at 5-HT2A, 5-HT2B and 5-HT2C serotonin receptors and structure-activity relationships of a series of cyproheptadine analogues. Chem Pharm Bull 1997; 45: 842-848.

29. Liston H, Bennett L, Usher B, Nappi J. The association of the combination of sumatriptan and methysergide infartion in a premenopausal woman. Arch Intern Med 1999; 159: 511-513.

30. Wolf $\mathrm{C}$, Schunack W. Synthesis and pharmacology of combined histamine H1-/H2-receptor antagonists containing diphenhydramine and cyproheptadine derivatives. Arch Pharm 1996; 329: 87-94

31. Shida T. A comparison of the pharmacological actions between DSCG (disodium cromoglycate) and BDP (beclomethasone dipropionate) in the treatment of bronchial asthma. Nippon Rinsbo 1996; 54: 3011-3016.

32. Businco L, Cantani A. Food allergy in children: diagnosis and treatment with sodium cromoglycate. Allergol Immunopatbol (Madr) 1990; 18: 339-348.

33. Canetti C, Silva JS, Ferreira SH, Cunha FQ. Tumour necrosis factor-alpha 
and leukotriene $\mathrm{B}(\mathrm{H})$ mediate the neutrophil migration in immune inflammation. Br J Pharmacol 2001; 134: 1619-1628.

34. De Lima V, Bezerra MM, de Menezes Alencar VB, Vidal FD, da Rocha FA, de Castro Brito GA, de Albuquerque Ribeiro R. Effects of chlorpromazine on alveolar bone loss in experimental periodontal disease in rats. Eur J Oral Sci 2000; 108: 123-129.

35. Nisijiima K, Yoshino T, Yui K, Katoh S. Potent serotonin $(5-\mathrm{HT})(2 \mathrm{~A})$ receptor antagonists completely prevent the development of hyperthermia in na animal model of the 5-HT syndrome. Brain Res 2001; 890 : $23-31$
36. Trichard C, Paillere-Martinot ML, Attar-Levy D, Recassens C, Monnet F, Martinot JL. Binding of antipsychotic drugs to cortical 5-HT2A receptors: a PET study of chlorpromazine, clozapine, and amisulpride in schizophrenic patients. Am J Psychiatry 1998; 155: 505-508.

Received 2 January 2002 


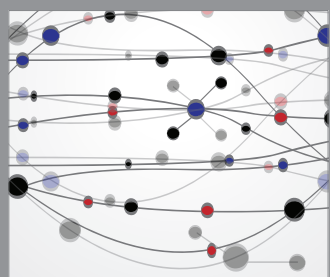

The Scientific World Journal
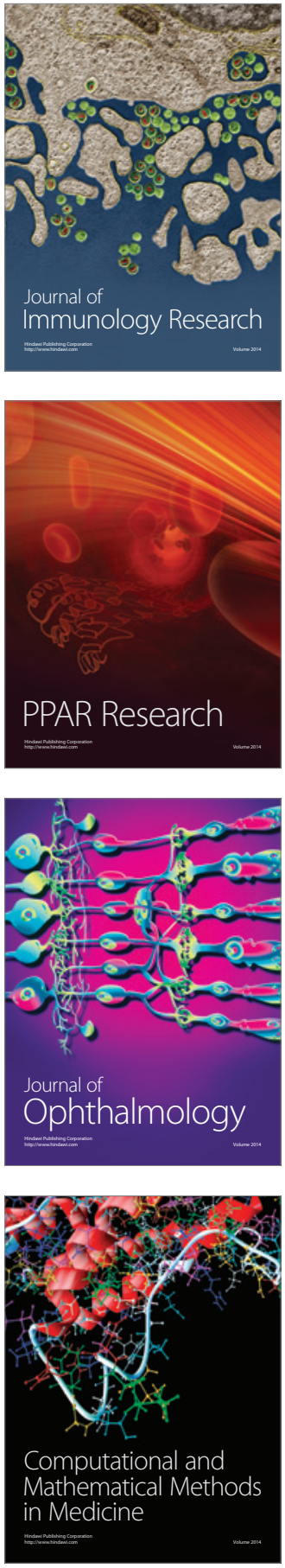

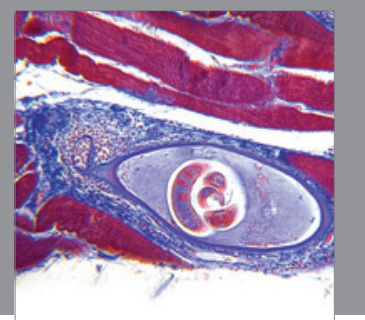

Gastroenterology

Research and Practice
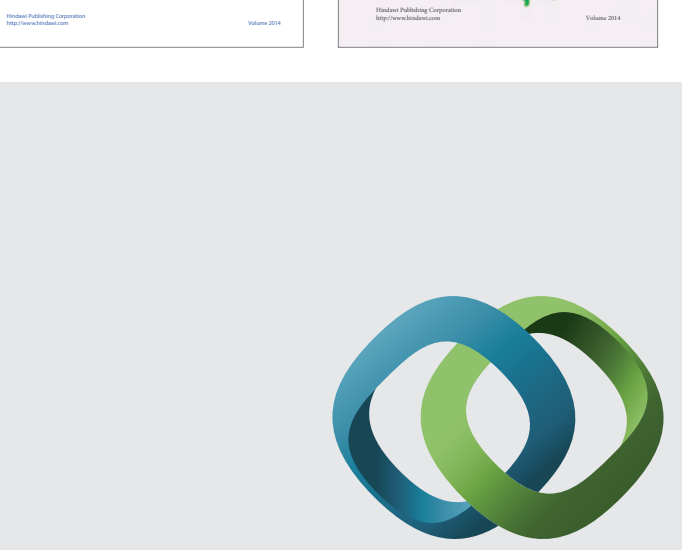

\section{Hindawi}

Submit your manuscripts at

http://www.hindawi.com
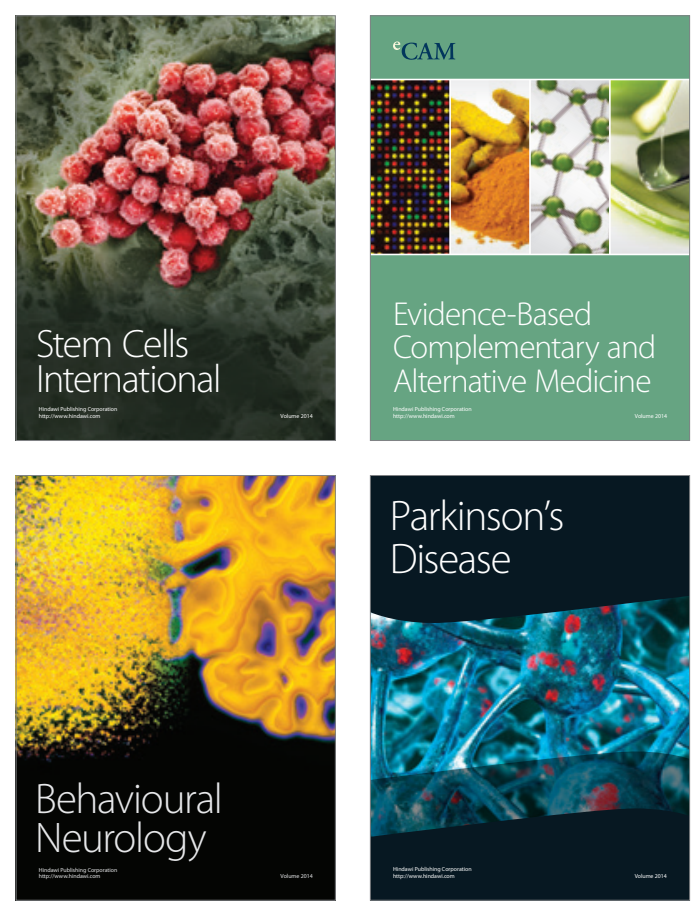

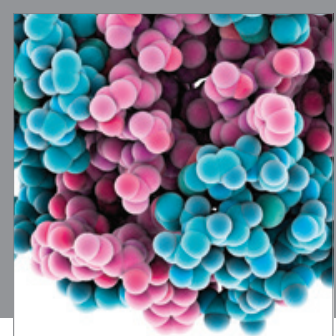

Journal of
Diabetes Research

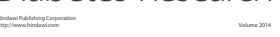

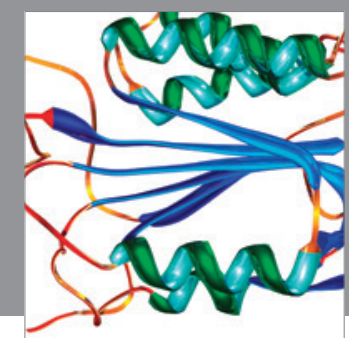

Disease Markers
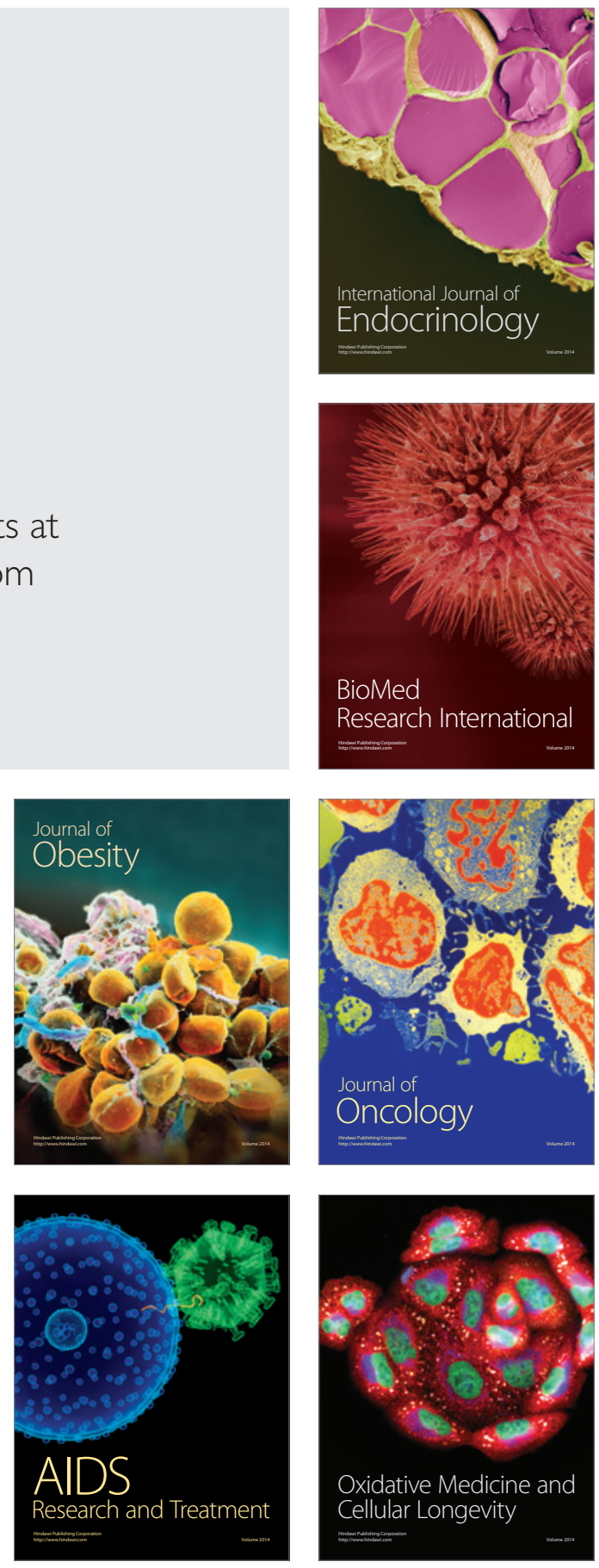